\title{
First and Second Law to Analyze the Performance of Bagasse Boilers*
}

\author{
J. H. Sosa-Arnao ${ }^{1 * *}$, S. A. Nebra ${ }^{2}$ \\ Research \& Development, Equipalcool Sistemas Ltda ${ }^{1}$ \\ Santo Onofre Street 299, Industrial, Sertãozinho São Paulo, Brazil. \\ Interdisciplinary Center of Energy Planning, State University of Campinas - NIPE/Unicamp ${ }^{2}$ \\ P.O.Box 1170; 1308-9714, Campinas, S.P., Brazil \\ E-mail: ${ }^{1}$ juan@equipalcool.com.br
}

\begin{abstract}
The performance of sugar cane bagasse boilers is commonly analyzed through the first law of thermodynamics, using the energy balance method and the fuel lower heating value as calculation base. This work presents a first law analysis using two different methods: the input/output and the energy balance. The employment of the fuel higher and lower heating values as calculation base are presented and discussed. Moreover, a second law analysis is showed, based on two methods: input/output and exergy balance. The methods based on exergy concept permits to observe the main irreversibilities that happen during the steam production in a bagasse boiler.
\end{abstract}

\section{Keywords: Boiler; efficiency; exergy; bagasse.}

\section{Introduction}

The sugar cane bagasse boiler efficiency is the most important parameter in sugar mill cogeneration systems; therefore, its calculation helps in cogeneration system optimization. The bagasse boiler development has followed the coal boiler technology. Also, the method to determine the bagasse boiler efficiency has been adopted from those used for coal boilers (ASME PTC 4.1, 1975; ASME PTC 4, 1998). However, the coal and bagasse fuels are very different, for instance the moisture content of bituminous coal is around 2,9\%, while that for bagasse is around $50 \%$. Consequently, some special considerations become necessary along the analysis of boiler efficiency of a wet fuel, such as bagasse.

In the literature, a methodology can be found recommended by Beaton and Lora to determine the bagasse boiler efficiency (Beaton and Lora, 1991). These authors calculated the bagasse boiler efficiency using LHV (Lower Heating Value) as the calculation base. In 1995, Acosta calculated the bagasse boiler efficiency using the HHV (Higher Heating Value) as the calculation base. Sosa-Arnao et al. (2006a) discussed these proposals and concluded that due to the high bagasse moisture content, using the HHV as the calculation base is more adequate.

On the second law analysis applied to bagasse boilers, several works can be found using the input/output method (Prieto and Nebra, 2004; Sosa-Arnao et al. 2006a; SosaArnao and Nebra 2006b and 2007), even though the analysis through this method does not permit to see the irreversibilities that happens in each process in the bagasse boiler. On the other hand, few works in this area have been published (Lozano, 1987; Cortez and Gómes, 1998; Kamate and Gangavati, 2010), and therefore this work aims to identify the main irreversibilities, seeking to reduce them. The methodology recommended can be extended to other kinds of boilers.

\section{Boiler Efficiency}

Figure 1a and 1b shows a schematic diagram of a bagasse boiler and a photograph of the sugar cane bagasse boiler installed in Colombo II mill (Palestina, São Paulo, Brazil) and manufactured by Equipalcool Sistemas Ltda (Sertaozinho, São Paulo State, Brazil).

In the Figure 1a, the main pieces of equipment that compose a bagasse boiler can be observed (furnace, air heater, economizer, multicyclone and scrubber).

Moreover, Figure 2 shows the scheme of thermodynamic analysis applied to a bagasse boiler, discussed in this work.

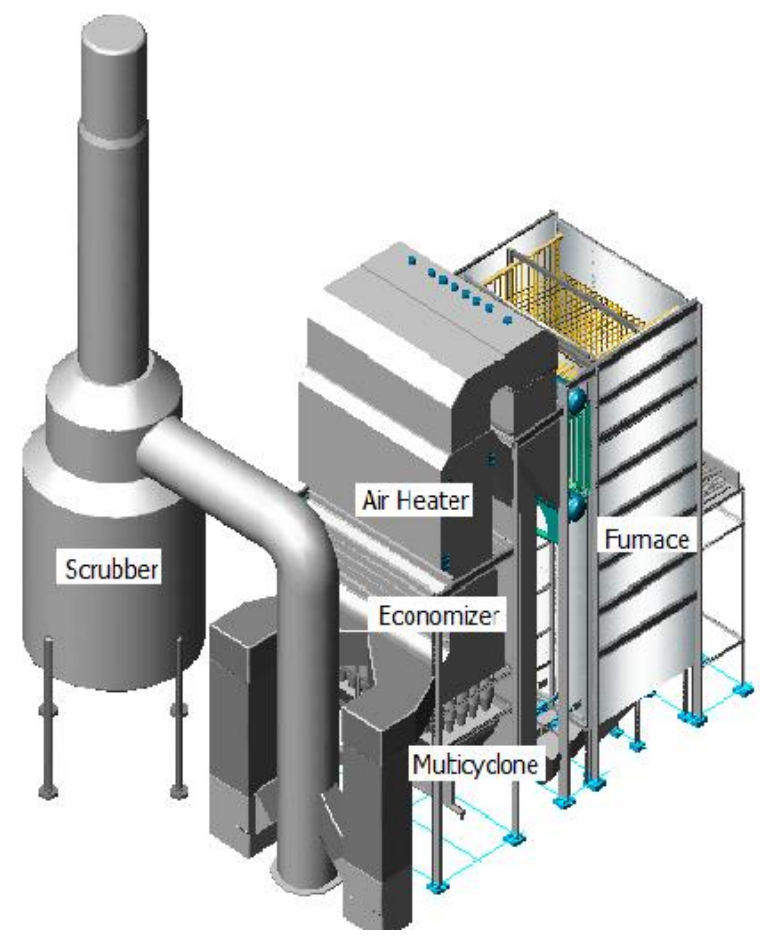

Figure 1a: Schematic diagram of a bagasse boiler.

*The organizers of ECOS'09 selected this paper as one of the conference's best papers, recommended it be considered for publication in IJoT, and managed the review process. It is printed here with permission of the authors and ECOS'09 organizers. 


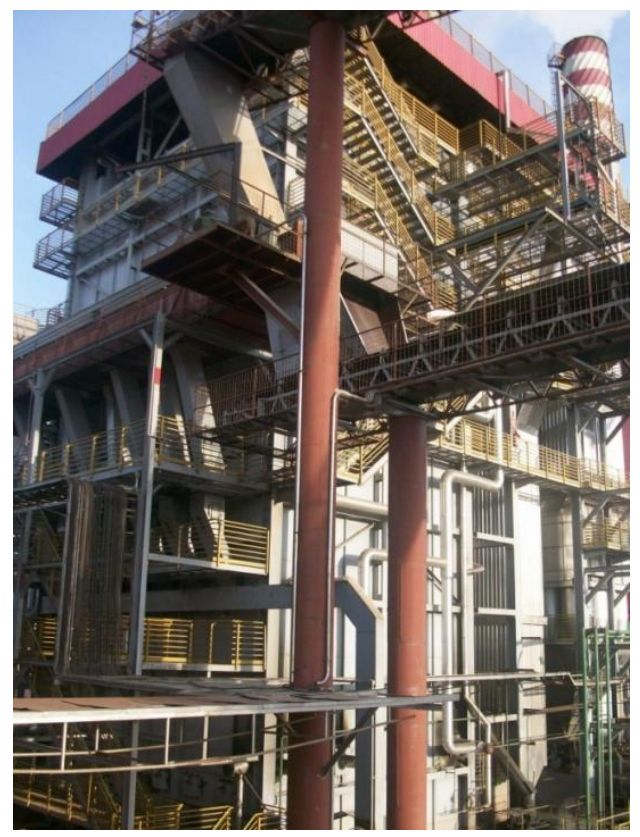

Figure 1b: Bagasse boiler installed in Colombo II mill, (courtesy Equipalcool Sistemas Ltda).

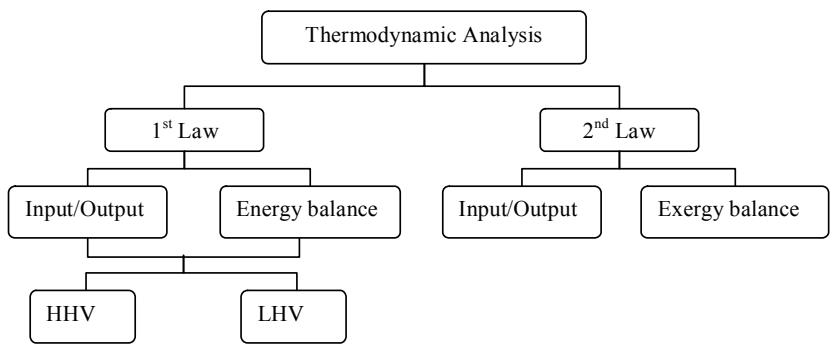

Figure 2: Thermodynamic analysis applied to bagasse boiler.

The first law analysis uses two methods: input/output and energy balance and both can use the higher and lower heating values as the calculation base.

\subsection{Input / Output $1^{\text {st }}$ Law Analysis:}

The first law efficiency in the input / output method is calculated by Eq. (1):

$$
\eta_{\text {boiler }}=\left(\frac{\dot{m}_{s}\left(h_{s}-h_{w, o}\right)}{\dot{m}_{b} H H V_{b}}\right) 100
$$

\subsection{Energy Balance $1^{\text {st }}$ Law Analysis}

The boiler first law efficiency was obtained through two proposals: Beatón and Lora (1991) and code ASME PTC 4.1 (1998). This last one was adapted to bagasse boilers, since it has been formulated for coal boilers.

\subsubsection{Beatón and Lora's Proposal:}

In this proposal, the heat absorbed to evaporate the water formed by oxidation of bagasse hydrogen content and also by bagasse moisture content are discounted in the lower heating value calculation (LHV).

The boiler efficiency is determined from the sum of all heat loss fractions, Eq. (2).

$$
\eta_{\text {boiler }}=100-\left(\mathrm{q}_{2}+\mathrm{q}_{3}+\mathrm{q}_{4}+\mathrm{q}_{5}+\mathrm{q}_{6}+\mathrm{q}_{7}\right)
$$

where the heat losses are expressed in percentage (\%) and are due to:

$\mathrm{q}_{2}$ : exhaust gases; $\mathrm{q}_{3}$ : incomplete chemical combustion; $\mathrm{q}_{4}$ : incomplete combustion due to mechanical causes; $\mathrm{q}_{5}$ : surface radiation and convection; $\mathrm{q}_{6}$ : slag and ashes $(\%) ; \mathrm{q}_{7}$ : bleeding in the boiler.

i) Exhaust gases heat losses $\left(\mathrm{q}_{2}\right)$ : among all heat loss fractions, this is the most significant; it is function of exhaust gas temperature (Beaton and Lora, 1991). Eq. (3) allows calculating it:

$$
q_{2}=\frac{\dot{m}_{g}\left(h_{g, \text { out }}-h_{g, o}\right)}{\dot{m}_{b} q_{a}} \cdot\left(100-q_{4}\right)
$$

Where: $m_{g} ; m_{b}$ : flue gas and bagasse mass flow, respectively $(\mathrm{kg} / \mathrm{s}) ; h_{g, \text { out }} ; h_{g, o}:$ specific enthalpy of flue gas at boiler outlet and reference state $(\mathrm{kJ} / \mathrm{kg}) ; q_{a}$ : available heat of bagasse - LHV ( $\mathrm{kJ} / \mathrm{kg})$.

(ii) Incomplete chemical combustion heat losses $\left(\mathrm{q}_{3}\right)$ : these losses are related to $\mathrm{CO}, \mathrm{H}_{2}$ and $\mathrm{CH}_{4}$ formation, as well as other products resulting from an incomplete combustion. As the bagasse combustion is performed with an important quantity of air in excess, the possible presence of these elements was neglected, thus this loss was assumed equal to zero.

iii) Heat loss by incomplete combustion due to mechanical causes $\left(\mathrm{q}_{4}\right)$ : it corresponds to unburned fuel particles, that go out mixed with the ashes, or are carried by the exit gases. It is calculated by Eq. (4):

$$
\begin{gathered}
q_{4}=\left(\frac{a f_{g r} \cdot c f_{g r}}{100-c f_{g r}}+\frac{a f_{a h} \cdot c f_{a h}}{100-c f_{a h}}+\frac{a f_{w h} \cdot c f_{w h}}{100-c f_{w h}}\right) \\
{\left[\frac{L H V_{f, a s h} \cdot \dot{m}_{\mathrm{ash}} \cdot 100}{q_{a}}\right]}
\end{gathered}
$$

Where: $a f_{g r} ; a f_{a h} ; a f_{w h}$ : Fraction of ash content in bagasse at stoker, air heater and scrubber, respectively (\%); $c f_{g r} ; c f_{a h} ; c f_{w h}$ : carbon contained in the ash at stoker, air heater and scrubber, respectively $(\%) ; \dot{\mathrm{m}}_{\mathrm{ash}}$ : ash mass flow $(\mathrm{kg} / \mathrm{s})$. and $L H V_{f, a s h}$ : Lower Heating Value of fuel contained in the ash $(327.9 \mathrm{~kJ} / \mathrm{kg})$.

iv) Heat losses due to surface radiation and convection $\left(\mathrm{q}_{5}\right)$ : the correct way to calculate these losses would be equating all the heat exchanged by convection and radiation from the boiler walls to the environment, but, in practical terms, this work is very difficult, thus a solution for the $\mathrm{q}_{5}$ calculation is to use the ABMA standard radiation loss chart (ASME PTC 4.1, 1975); which is based on an average boiler wall temperature, measured by the staff. To use this abacus, its calculation basis (HHV) needed to be taken into account and converted to that used by Beatón and Lora. These 
authors also presented a chart to determine the radiation and convection boiler heat loss, but it is only function of steam mass flow and does not vary when different pressure and temperature of steam are used. So, it was not utilized. Another important aspect is that the radiation loss chart was obtained from coal boilers, which are of lower size than bagasse boilers (for the same capacity). This assumption was made because more information was not found about radiation heat loss in bagasse boilers.

v) Heat losses by slag and ashes $\left(\mathrm{q}_{6}\right)$ : the last lost fraction refers to sensible heat lost by slag and ashes. According Beaton and Lora (1991); this fraction is responsible for less than $0.1 \%$ of the available heat, and therefore can be neglected.

vi) Heat losses by bleeding in boiler $\left(\mathrm{q}_{7}\right)$ : it was considered as $2 \%$ of steam mass flow, according Acosta (1995).

\subsubsection{The Code ASME PTC 4.1 Proposal:}

This proposal requires the determination of losses, heat credits, ultimate analysis and higher heating value (HHV) of the fuel (ASME PTC 4.1, 1998). The heat losses, considered in the calculation, are the same that Beatón and Lora's propose $\left(\mathrm{q}_{3}, \mathrm{q}_{4}, \mathrm{q}_{5}\right.$, and $\left.\mathrm{q}_{6}\right)$, but the calculation base is the HHV. There are some differences in the analysis of boiler exhaust gas heat loss $\left(\mathrm{q}_{2}\right)$ between the two proposals. According to ASME PTC 4.1, this heat loss is divided into three: dried gas heat loss $\left(\mathrm{q}_{2}{ }^{*}\right)$, heat loss due to water vapor from burning hydrogen $\left(\mathrm{q}_{8}\right)$ and heat loss due to bagasse moisture content $\left(\mathrm{q}_{9}\right)$. The boiler efficiency is determined from the sum of all heat loss fractions, as a percentage of the available heat of bagasse, Eq. (5).

$$
\eta_{\text {boiler }}=100-\left(q_{2}^{*}+q_{3}+q_{4}+q_{5}+q_{6}+q_{7}+q_{8}+q_{9}\right)
$$

(i) Heat loss due to dry gas sensible heat $\left(\mathrm{q}_{2}{ }^{*}\right)$ : It represents the dry flue gas energy carried by it when it leaves the boiler and can be calculated by Eq. (6).

$$
q_{2}{ }^{*}=\frac{\dot{m}_{d g} h_{d g, \text { out }}\left(100-q_{4}^{*}\right)}{\dot{m}_{b} q_{a}^{*}}
$$

where: $\dot{m}_{d g}$ : dry flue gas mass flow $(\mathrm{kg} / \mathrm{s}) ; h_{d g, \text { out }}:$ specific enthalpy of dry flue gas at boiler outlet $(\mathrm{kJ} / \mathrm{kg})$;

$q_{a}^{*}$ : available heat of bagasse $-\mathrm{HHV}(\mathrm{kJ} / \mathrm{kg})$.

(ii) Heat loss due to evaporation of water formed from hydrogen in the fuel $\left(\mathrm{q}_{8}\right)$ : it represents the energy loss due to evaporation of water formed in the combustion from hydrogen contained in the fuel, which leaves the boiler with the flue gas.

$q_{8}=\frac{\dot{m}_{w, h}\left(h_{w, h}-h_{w, o}\right) \cdot 100}{\dot{m}_{b} q_{a}^{*}}$

Where: $\dot{m}_{w, h}$ : water vapor mass flow formed from hydrogen contained in the bagasse $(\mathrm{kg} / \mathrm{s}) ; h_{w, h} ; h_{w, o}$ : specific enthalpy of water vapor at boiler outlet and reference state, respectively $(\mathrm{kJ} / \mathrm{kg})$. (iii) Heat loss due to evaporation of water from bagasse moisture content $\left(\mathrm{q}_{9}\right)$ : this heat loss is most important due to the high bagasse moisture content (around 50\%). When a bagasse dryer is used in the boiler, this heat loss can be reduced (Sosa-Arnao and Nebra, 2009).

$q_{9}=\frac{\dot{m}_{w, b m c}\left(h_{w, b m c}-h_{w, o}\right) \cdot 100}{\dot{m}_{b} q_{a}^{*}}$

Where: $\dot{m}_{w, b m c}$ : water vapor mass flow formed from bagasse moisture content $(\mathrm{kg} / \mathrm{s}) ; h_{w, b m c} ; h_{w, o}:$ specific enthalpy of water vapor at boiler outlet and at reference state respectively $(\mathrm{kJ} / \mathrm{kg})$.

\subsection{Second Law Analysis}

This analysis can be performed through two methods: input/output and exergy balance. The first one is commonly used in the boiler analysis; the second one is proposed in this paper, as a calculation tool for the analysis of bagasse boilers performance.

\subsubsection{Input / Output Method:}

The boiler efficiency is determined by Eq. (9).

$\xi^{I}=\frac{\dot{m}_{s}\left(b_{s}-b_{w}\right) \cdot 100}{\dot{m}_{b} b_{b}}$

Where: $\dot{m}_{s}, \dot{m}_{b}$ : mass flow of steam and bagasse, respectively $(\mathrm{kg} / \mathrm{s}) ; b_{s}, b_{w}, b_{b}:$ specific exergy of steam, water and bagasse, respectively $(\mathrm{kJ} / \mathrm{kg})$.

\subsubsection{Exergy Balance Method:}

Commonly, this method has been applied to boilers fueled by coal. However, there are few works about exergy balance applied to bagasse boilers. Cardenas et. al. (1994), identified the exergy loss in several boiler devices (steam generator, air heater, and bagasse dryer). This analysis hides the irreversibilities associated with important processes, such as, bagasse drying, combustion and heat transfer, which happens in the steam generator.

Actually, the processes, such as bagasse drying, combustion and heat transfer between the flue gas and water/steam, happen simultaneously in the furnace; even though, aiming to get more information, they were separated following the procedure recommended by Kotas (1995). The boiler exergetic efficiency, through the exergy balance method, can be determined by Eq. (10)

$$
\xi^{I I}=100-\left(b_{2}+b_{3}+b_{4}+b_{5}+b_{6}+b_{7}+b_{8}\right)
$$

Where the irreversibilities, in percentage, are due to: $b_{2}$ : adiabatic combustion of dry bagasse; $b_{3}$ : mixture and evaporation of bagasse moisture content; $b_{4}$ : heat transfer between flue gas and steam generator; $b_{5}$ : heat transfer between flue gas and water into the economizer; $b_{6}$ : heat transfer between flue gas and air into the air heater; $b_{7}$ : drying of bagasse in the bagasse dryer; and, $b_{8}$ : mixture of flue gas into the environment. 


\subsubsection{Control Volume (C.V):}

The analysis of bagasse boiler was divided into seven control volumes: combustion, mixture, steam generator, economizer, air heater, dryer and chimney. Figure 3 shows them. The C.V. named "combustion" and "mixture" are virtual, introduced only for the sake of analysis and improvement; in fact, both processes happen at the same time. The evaporation of the remaining bagasse moisture was included in the virtual "mixture" C.V. in spite of the fact it happens in the boiler, prior to the combustion.

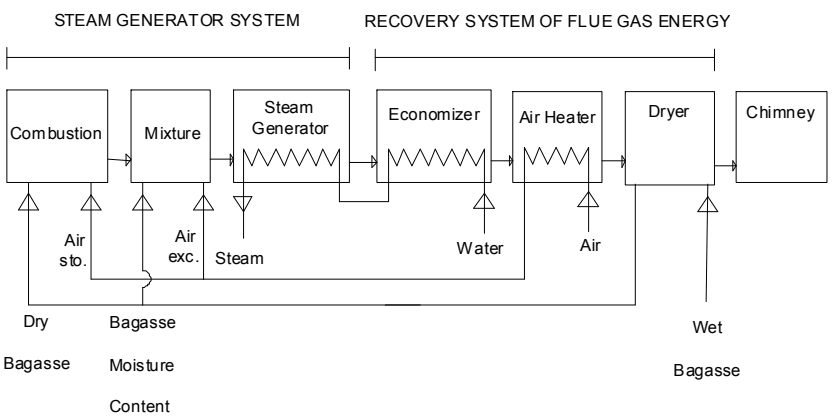

Figure 3: Control volumes considered in the bagasse boiler analysis.

i) Combustion: in this control volume, it is considered that the combustion process of dry bagasse, at stoichiometric conditions, happens. The dry bagasse (containing some remaining water) comes from the dryer and the stoichiometric air, from the air heater.

$b_{2}=\frac{I_{c o m}}{B_{b}}=\frac{\left(\dot{m}_{d b} b_{d b}+\dot{m}_{a, s t} b_{a}-\dot{m}_{d g} b_{d g}\right) \cdot 100}{\dot{m}_{b} b_{b}}$

Where: $\dot{m}_{d b} ; \dot{m}_{d g} ; \dot{m}_{a, s t}:$ mass flow of dried bagasse, dried gas and stoichiometric air, respectively $(\mathrm{kg} / \mathrm{s}) ; b_{d b} ; b_{d g} ; b_{a, s t}$ : specific exergy of dried bagasse, dried gas and stoichiometric air, respectively $(\mathrm{kJ} / \mathrm{kg})$ and $I_{\text {com }} ; B_{b}$ : combustion irreversibility and bagasse exergy $(\mathrm{kW})$.

ii) Mixture: In this control volume, it was considered that the evaporation process of remaining bagasse moisture content and its mixture with dry flue gas and excess air happens.

$b_{3}=\frac{\left(\dot{m}_{d g} b_{d g}+\dot{m}_{w, b m c} b_{w, b m c}+\dot{m}_{a, e} b_{a, e}-\dot{m}_{g} b_{g}\right) \cdot 100}{\dot{m}_{b} b_{b}}$ $b_{3}=\frac{I_{m i x}}{B_{b}}$

Where:

$b_{w, b m c} ; b_{a, e} ; b_{g}:$ specific exergy of bagasse moisture content, excess air and wet gas, respectively $(\mathrm{kJ} / \mathrm{kg})$ and $I_{m i x}:$ mixture irreversibility $(\mathrm{kW})$.

iii) Steam Generator: the heat transfer between the flue gas and water/steam happens in this control volume. In the bagasse boiler, the steam generator is composed by water wall into furnace, super-heater, tubes bank and screen.

$b_{4}=\frac{I_{s g}}{B_{b}}=\frac{\left(\dot{m}_{g}\left(b_{g, \text { in }}-b_{g, \text { out }}\right)-\dot{m}_{s}\left(b_{s, \text { out }}-b_{w, \text { in }}\right)\right) \cdot 100}{\dot{m}_{b} b_{b}}$

Where: $b_{g, \text { in }} ; b_{g, \text { out }}:$ specific exergy of flue gas at steam generator inlet and outlet $(\mathrm{kJ} / \mathrm{kg}) ; b_{s, \text { out }} ; b_{w, \text { in }}:$ specific exergy of steam and water $(\mathrm{kJ} / \mathrm{kg}) ; I_{s g}$ : heat transfer irreversibility into steam generator $(\mathrm{kW})$.

iv) Economizer: the heat transfer between the flue gas and boiler fed liquid water happens in this control volume.

$b_{5}=\frac{I_{e c o}}{B_{b}}=\frac{\left(\dot{m}_{g}\left(b_{g, \text { in }}-b_{g, \text { out }}\right)-\dot{m}_{w}\left(b_{w, \text { out }}-b_{w, \text { in }}\right)\right) \cdot 100}{\dot{m}_{b} b_{b}}$

Where:

$b_{w, \text { in }} ; b_{w, \text { out }}:$ specific exergy of water at economizer inlet and outlet $(\mathrm{kJ} / \mathrm{kg})$;

$I_{\text {eco }}$ : heat transfer irreversibility into economizer $(\mathrm{kW})$.

v) Air Heater: in this control volume, the heat transfer between the flue gas and the air used in the combustion process and the overfire happens.

$b_{6}=\frac{I_{a h}}{B_{b}}=\frac{\left(\dot{m}_{g}\left(b_{g, \text { in }}-b_{g, \text { out }}\right)-\dot{m}_{a}\left(b_{a, \text { out }}-b_{a, \text { in }}\right)\right) \cdot 100}{\dot{m}_{b} b_{b}}$

Where: $b_{a, \text { in }} ; b_{a, \text { out }}$ : specific exergy of air at air heater inlet and outlet $(\mathrm{kJ} / \mathrm{kg})$ and $I_{a h}$ : heat transfer irreversibility into air heater $(\mathrm{kW})$.

vi) Dryer: the bagasse moisture content is reduced in this control volume. It was assumed that the drying process is carried out using the system's own flue gas generated in the bagasse boiler;

$b_{7}=\frac{\left(\dot{m}_{g}\left(b_{g, \text { in }}-b_{g, \text { out }}\right)-\dot{m}_{d b} \Delta b_{d b}-\dot{m}_{w, b m c} \Delta b_{w}\right) \cdot 100}{\dot{m}_{b} b_{b}}$

$b_{7}=\frac{I_{d}}{B_{b}}$

Where: $\Delta b_{d b}$ : specific exergy variation of dry bagasse at the dryer inlet and outlet $(\mathrm{kJ} / \mathrm{kg}) ; \Delta b_{w}$ : specific exergy variation of water contained in the bagasse at the dryer inlet and outlet $(\mathrm{kJ} / \mathrm{kg}) ; m_{d b} ; m_{w, b m c}$ : mass flow of dry bagasse and water (bagasse moisture content) (kg/s); $I_{d}$ : irreversibility associated to bagasse drying $(\mathrm{kW})$. 
vii) Chimney: this virtual control volume was created to consider the process of leading the flue gas until thermal and chemical equilibrium with the environment. Therefore, this parameter is composed by physical and chemical exergy.

$b_{8}=\frac{I_{s t} \cdot 100}{B_{b}}$

Where $I_{s t}$ : irreversibility due to thermal and chemical disequilibrium of flue gas with the environment $(\mathrm{kW})$.

\subsubsection{Exergy of Sugar Cane Bagasse:}

There are two methodologies to determine the exergy of sugar cane bagasse: That one proposed by Szargut et al. (1988) for wood exergy calculation and that of Wittwer (1991). Even though, the exergy of sugar cane bagasse is adapted from wood exergy calculation, the Szargut et al. methodology is as adequate as Wittwer's methodology, which was developed specifically for bagasse, according to Sosa-Arnao and Nebra (2005).Therefore, Szargut, et al. methodology was adopted. The bagasse exergy calculation is determined through the following equations:

$$
\beta=\frac{\left\{\begin{array}{l}
1.0412+0.2160\left(\frac{{ }^{z} H_{2}}{{ }^{z} C}\right)-0.2499\left(\frac{{ }^{z} O_{2}}{{ }^{z} C}\right) \\
\times\left[1+0.7884\left(\frac{{ }^{z} H_{2}}{{ }^{z} C}\right)\right]-0.0450\left(\frac{{ }^{z} N_{2}}{{ }^{z} C}\right)
\end{array}\right\}}{1-0.3035\left(\frac{{ }^{z} O_{2}}{{ }^{z} C}\right)}
$$

Where: $z_{H_{2}}, z_{c}, z_{O 2}, z_{N 2}$ are mass fractions of hydrogen, carbon, oxygen, nitrogen, respectively.

$$
b_{b}^{c}=\beta\left(L H V+\lambda z_{w}\right)+9683 z_{s}+b_{a s h}^{c} z_{a s h}+b_{w}^{c} z_{w}
$$

Where $b_{b}^{c}$ : specific chemical exergy of cane bagasse $(\mathrm{kJ} / \mathrm{kg}) ; \lambda$ :vaporization heat $(\mathrm{kJ} / \mathrm{kg}) ; z_{w}, z_{s}, z_{\text {ash }}$ : Mass fraction of water, sulphur and ash in fuel; $b_{a s h}^{c}, b_{w}^{c}:$ specific chemical exergy of ash and water respectively $(\mathrm{kJ} / \mathrm{kg})$.

\subsubsection{Chemical Composition of Dried Bagasse:}

The average values reported by Van der Poel et al. (1998) were used, where: carbon $47,2 \%$; hydrogen $6,3 \%$; Nitrogen $0,3 \%$; Oxygen $44,5 \%$; Sulphur $0,1 \%$ and ash $2,5 \%$.

\section{Steam Generators System Analyzed}

Aiming to show the application of efficiency boiler calculation methodology, four different boiler arrangements were studied: i) steam generator, high and low temperature economizer and air heater; ii) steam generator, air heater and economizer; iii) steam generator, air heater and bagasse dryer and iv) steam generator, economizer, air heater and bagasse dryer. (See Figures 4 to 7). The first arrangement is commonly used in new boiler projects; the second one is also used in sugar mills. Currently, the third and four arrangements are not used, but they have been included in this work as new proposals. The boiler capacity considered for simulations was $200 \mathrm{t} / \mathrm{h}$ of steam mass flow at $6.5 \mathrm{MPa}$ and $520^{\circ} \mathrm{C}$

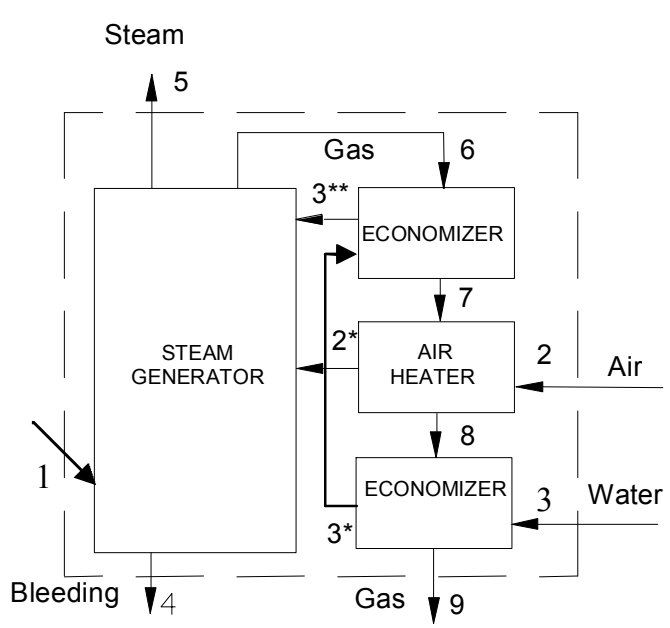

Figure 4: Case I: Boiler system composed of steam generator, high and low temperature economizer and air heater.

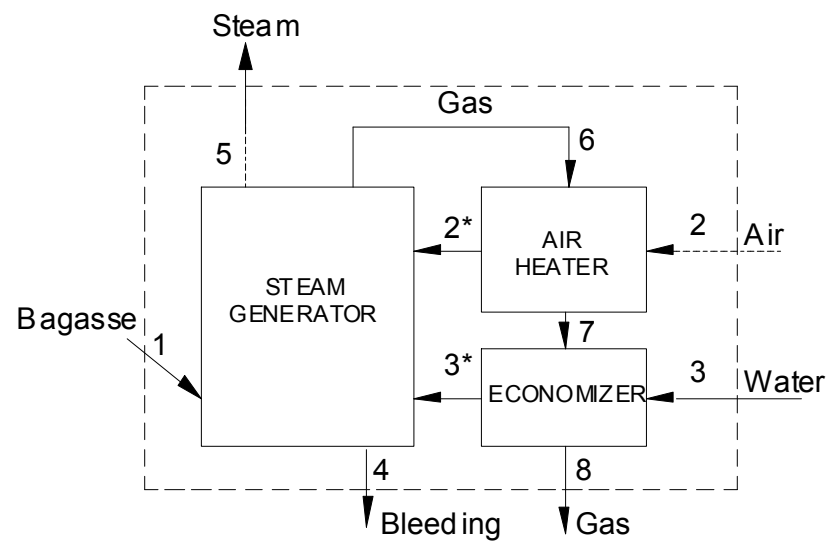

Figure 5: Case II: Boiler system composed of steam generator, air heater and economizer.

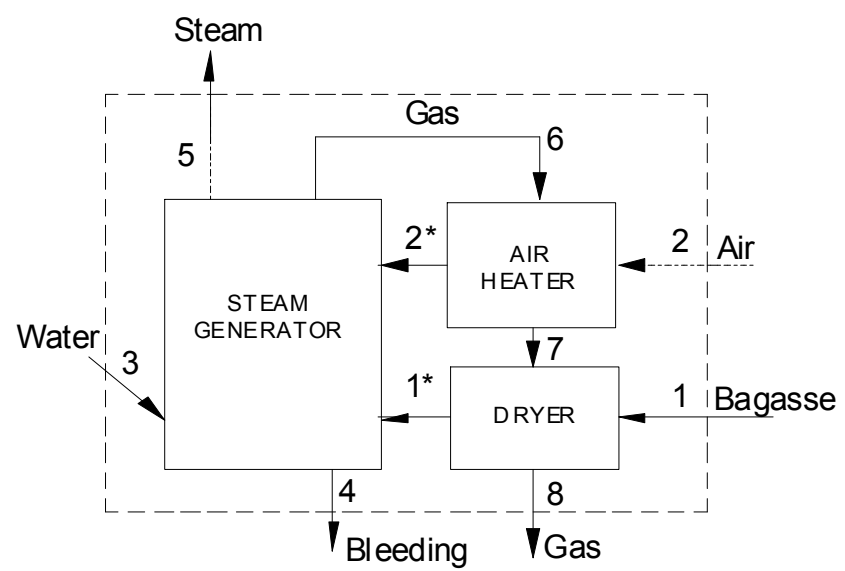

Figure 6: Case III: Boiler system composed of steam generator, air heater and bagasse dryer. 


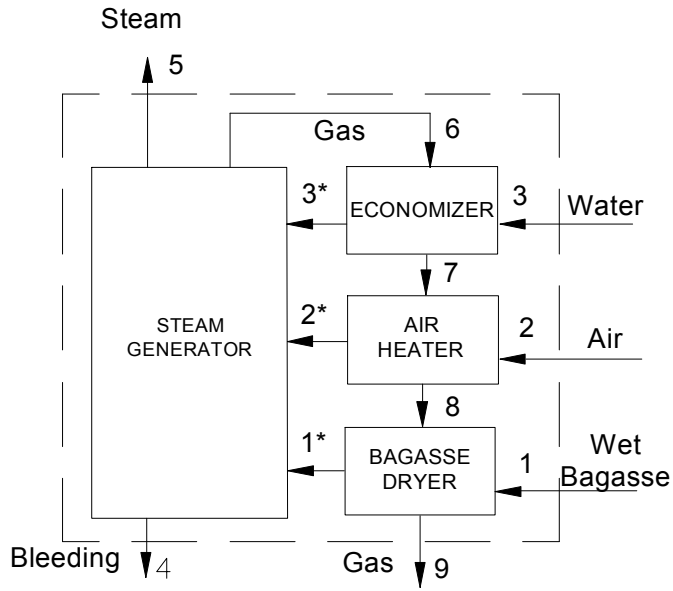

Figure 7: Case IV: Boiler system composed of steam generator, economizer, air heater and bagasse dryer.

Table 1: Thermodynamics data of boiler systems, cases I, II, III and IV (200 t/h at 6,5MPa, and $\left.500^{\circ} \mathrm{C}\right)$.

\begin{tabular}{|r|r|r|r|r|r|r|r|r|r|r|r|r|}
\hline Flux & \multicolumn{4}{|c|}{ Temperature } & \multicolumn{3}{c|}{ Pressure } & \multicolumn{5}{c|}{ Mass flow } \\
& \multicolumn{4}{|c|}{$\left[{ }^{\circ} \mathrm{C}\right]$} & \multicolumn{3}{c|}{$[\mathrm{MPa}]$} & \multicolumn{4}{c|}{$[\mathrm{kg} / \mathrm{s}]$} \\
\hline & \multicolumn{1}{|c|}{ I } & \multicolumn{1}{|c|}{ II } & III & IV & I & II & III & IV & I & II & III & IV \\
\hline 1 & 35 & 35 & 35 & 35 & 1 & 1 & 1 & 1 & 24.78 & 24.78 & 22.96 & 22.96 \\
\hline $1^{*}$ & - & - & 74.55 & 74.55 & - & - & 1 & 1 & & & 17.52 & 17.52 \\
\hline 2 & 30 & 30 & 30 & 30 & 1 & 1 & 1 & 1 & 95.02 & 95.02 & 75 & 75 \\
\hline $2^{*}$ & 235.2 & 240.2 & 288.3 & 147.5 & 1 & 1 & 1 & 1 & 95.02 & 95.02 & 75 & 75 \\
\hline 3 & 120 & 120 & 120 & 120 & 7.2 & 7.2 & 6.9 & 7.2 & 60.64 & 60.64 & 60.3 & 60.3 \\
\hline $3^{*}$ & 138.7 & 170.8 & & 165.4 & 7.0 & 6.9 & - & 6.9 & 60.64 & 60.64 & & 60.3 \\
\hline $3^{* *}$ & 172.6 & - & - & - & 6.9 & & - & - & 60.64 & & & \\
\hline 4 & 280.9 & 280.9 & 280.9 & 280.9 & 6.5 & 6.5 & 6.5 & 6.5 & 5.08 & 5.08 & 4.74 & 4.74 \\
\hline 5 & 500 & 500 & 500 & 500 & 6.5 & 6.5 & 6.5 & 6.5 & 55.56 & 55.56 & 55.56 & 55.56 \\
\hline 6 & 400.9 & 400.9 & 400.9 & 400.9 & 1 & 1 & 1 & 1 & 119.8 & 119.8 & 97.96 & 97.96 \\
\hline 7 & 340 & 260 & 215 & 300 & 1 & 1 & 1 & 1 & 119.8 & 119.8 & 97.96 & 97.96 \\
\hline 8 & 200 & 165 & 74.55 & 215 & 1 & 1 & 1 & 1 & 119.8 & 119.8 & 97.96 & 97.96 \\
\hline 9 & 165 & & & 74.55 & 1 & & & 1 & 119.8 & & & 97.96 \\
\hline
\end{tabular}

Table 1 shows the primary values considered on the boiler simulation for the four arrangements studied. The (water, bagasse and air) mass flow positions are indicated with numbers. More details about this simulation can be found in Sosa-Arnao and Nebra (2007).

These results were obtained from simulations done using energy and mass balance for several sections of the bagasse boiler. Also, these results presented good agreement when compared with measured ones "in loco" (Sosa-Arnao, 2007).

The first and second arrangements present the same value of outlet flue gas temperature $\left(165^{\circ} \mathrm{C}\right)$; while, in the third and fourth ones, this temperature was lower $\left(74,55^{\circ} \mathrm{C}\right)$. This fact happens due to the bagasse dryer being the last energy recovery piece of equipment. The advantage of its use compared with economizer or air heater is that it permits to reduce the gas temperature to lower values than those used in practical terms with the economizer and air heater.

Figure 8 and 9 shows Sankey's diagrams, on LHV and HHV calculation base, corresponding to first and second arrangements (cases I and II). Figure 8 shows that the highest energy loss is represented by exhaust gas $\left(\mathrm{q}_{2}=10.21 \%\right)$; while in Figure 9, it is represented by the evaporation of water from bagasse moisture content $\left(\mathrm{q}_{9}=16.35 \%\right)$ and the evaporation of water from the hydrogen contained in the fuel $\left(\mathrm{q}_{8}=9.50 \%\right)$. The boiler efficiency analysis, on LHV as calculation base, hides the effect of water evaporation from bagasse moisture content and those formed from hydrogen in the fuel; since this effect is discounted in the LHV calculation.

The cases I and II present the same boiler efficiency values, due to the outlet flue gas temperature of both systems being the same. The boiler efficiency obtained agrees with those reported by Brazilian boiler manufacturers (Sosa-Arnao, et al. 2007).

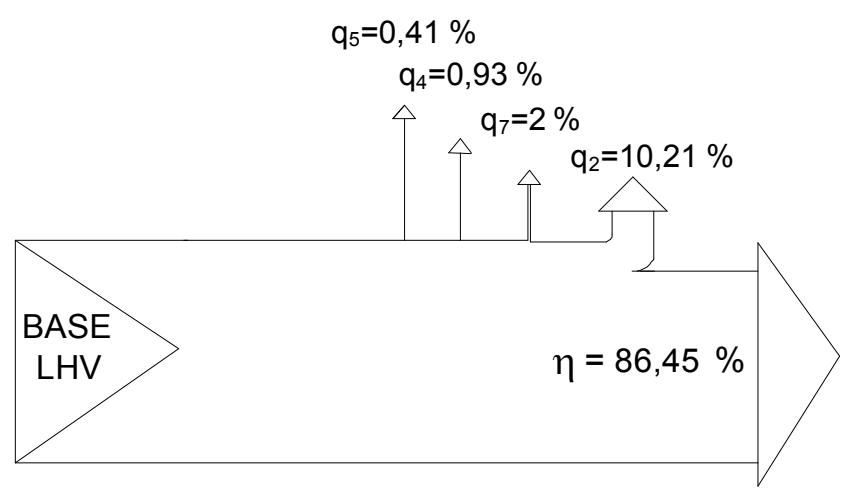

Figure 8: Sankey's diagram for cases I and II (LHV as calculation base).

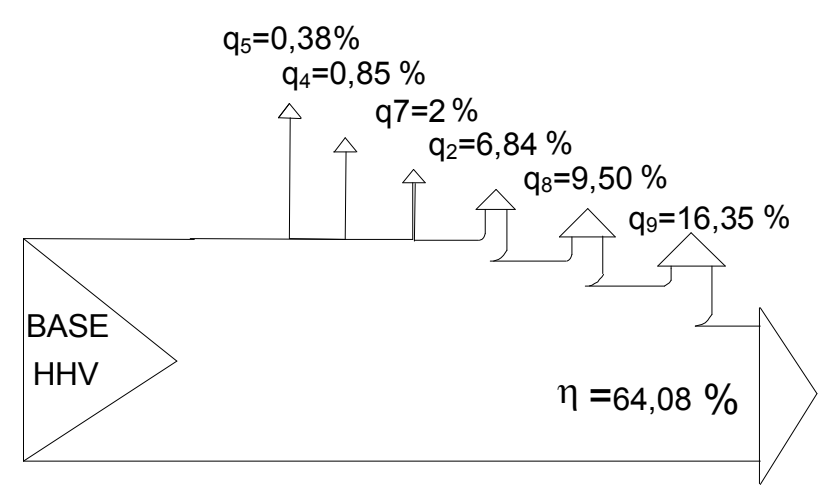

Figure 9: Sankey's diagram for cases I and II (HHV as calculation base).

Figures 10 and 11 shows the Sankey's diagrams for cases III and IV. The boiler efficiency obtained through these arrangements $(93.3 \%$ and $70.39 \%)$ were higher than cases I and II $(86.45 \%$ and $64.08 \%)$. This fact happens due to the outlet flue gas temperature $\left(74.55^{\circ} \mathrm{C}\right)$ being lower than in cases I and II $\left(155^{\circ} \mathrm{C}\right)$. Currently, there are some bagasse boilers operating with dryers, and they attain lower temperatures in the gas outlet, without corrosion problems. The boiler efficiency in cases III and IV agree with that reported by Sosa-Arnao, et al. (2006c).

Figures 12 and 13 show the Grasman's diagrams for cases I and II. These arrangements present similar boiler efficiencies, and also, the most important exergy destruction is represented by the adiabatic combustion of dry bagasse $\left(b_{2}=27.28\right.$ and $\left.27.21 \%\right)$, the second by the heat transfer into the steam generator $\left(b_{4}=17\right.$ and $\left.17.12 \%\right)$, the third by the mixture process $\left(b_{3}=12,67 \%\right.$ and $\left.12,66 \%\right)$ and finally the flue gas mixture into environment, chimney loss, $\left(b_{8}=10.48 \%\right)$, the others ones were lower than $2 \%$. 


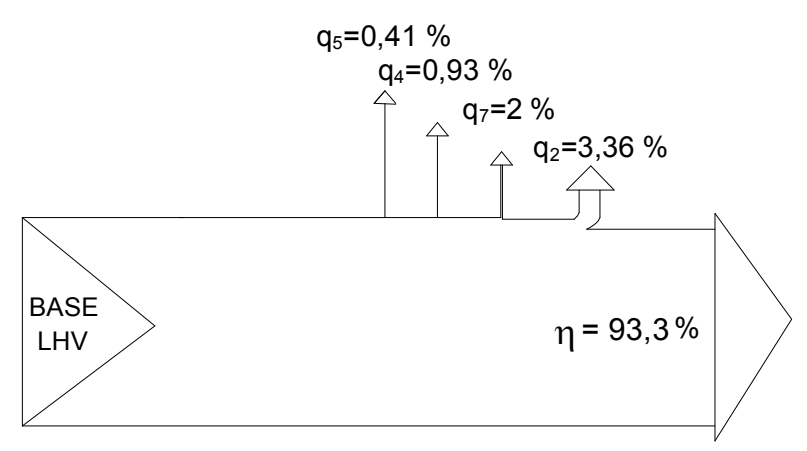

Figure 10: Sankey diagram for cases III and IV, LHV base.

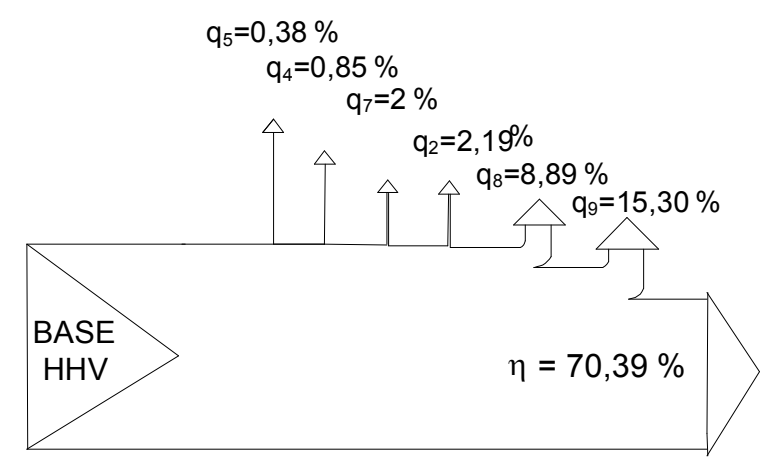

Figure 11: Sankey diagram for cases III and IV, HHV base.

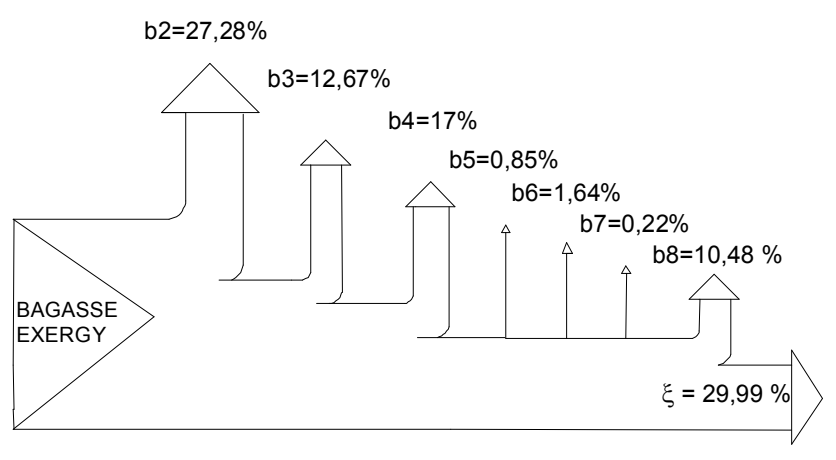

Figure 12: Grassman diagram for case I.

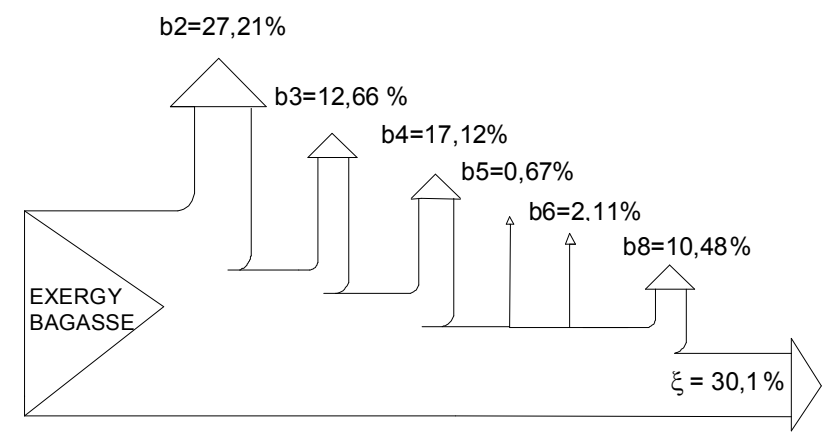

Figure 13: Grassman diagram for case II.

Figures 14 and 15 show the Grasman's diagram for cases III and IV, respectively. In these systems the most important exergy destruction is represented by the adiabatic combustion of dry bagasse $\left(b_{2}=26.6\right.$ and $\left.28.62 \%\right)$; the second, by the heat transfer into the steam generator $\left(b_{4}=22.84\right.$ and $\left.19.9 \%\right)$; the third, by the flue gas mixture into the environment, chimney loss, $\left(b_{8}=9.1 \%\right)$, and finally by the (virtual) mixture process $\left(b_{3}=7.17 \%\right.$ and $\left.7.45 \%\right)$. The others ones are lower than $2 \%$.

The cases III and IV present higher boiler efficiencies $(31.9 \%)$ than those corresponding to cases I and II (30\%). The main difference is represented by the exergy destruction in thermal and chemical equilibrium of flue gas into the environment $\left(b_{8}=10.48\right.$ and $\left.9.1 \%\right)$.

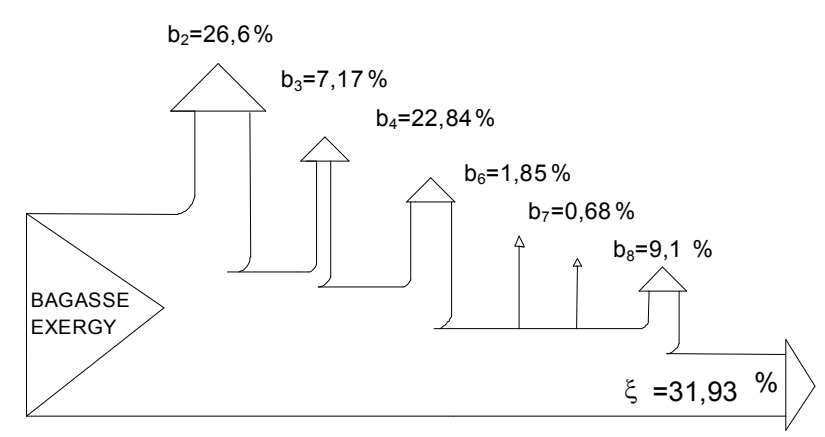

Figure 14: Grassman's diagram for case III.

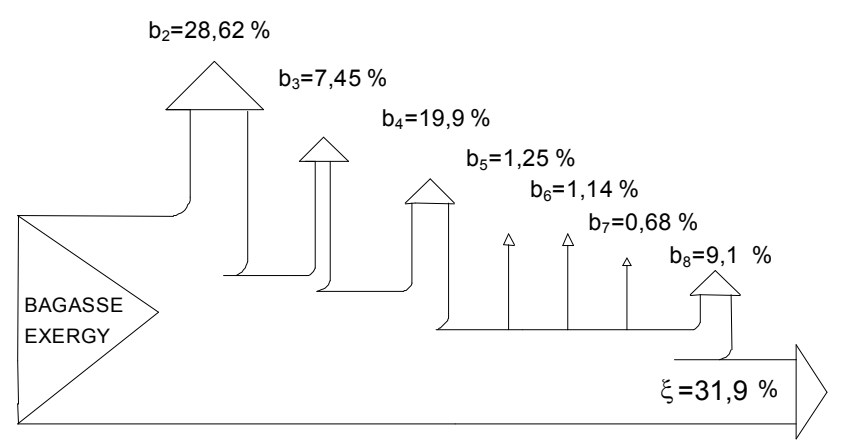

Figure 15: Grassman's diagram for case IV.

The boiler efficiency by first law is blind to the steam boiler parameters increase, since its main parameter to evaluate the boiler efficiency is the outlet flue gas temperature. Therefore, the application of the second law is necessary to determine the boiler performance. Table 2 shows the effect of increasing the steam boiler parameter, it can be observed that when the steam pressure and temperature increase the exergetic efficiency increase too. In this analysis the same equipment schemes were considered as in cases I, II, III and IV as shown in Figs. 3, 4,5 and 6 .

Table 2: Boiler efficiency, by first and second law, for several steam boiler pressure and temperature levels

\begin{tabular}{|c|c|c|c|c|c|c|}
\hline \multirow[t]{2}{*}{ Efficiency } & \multicolumn{4}{|c|}{$\eta(\%)$} & \multirow{2}{*}{\multicolumn{2}{|c|}{$\frac{\xi}{(\%)}$}} \\
\hline & \multicolumn{2}{|c|}{ LHV } & \multicolumn{2}{|c|}{ HHV } & & \\
\hline Cases & I and II & III and IV & I and II & III and IV & \begin{tabular}{l|l|} 
I & II \\
\end{tabular} & \begin{tabular}{|l|l|} 
III & IV \\
\end{tabular} \\
\hline $\begin{array}{c}2 \mathrm{MPa} \text { and } \\
300^{\circ} \mathrm{C}\end{array}$ & 86.5 & 93.3 & 64.1 & 70.4 & 25.7 & 27.3 \\
\hline $\begin{array}{c}6.5 \mathrm{MPa} \\
\text { and } 500^{\circ} \mathrm{C} \\
\end{array}$ & 86.5 & 93.3 & 64.1 & 70.4 & 30.2 & 32.1 \\
\hline $\begin{array}{c}12 \mathrm{MPa} \\
\text { and } 520^{\circ} \mathrm{C}\end{array}$ & 86.5 & 93.3 & 64.1 & 70.4 & 31.9 & 34 \\
\hline
\end{tabular}

\section{Conclusions}

Presented in this work is the first and second laws of thermodynamics applied to determine bagasse boiler efficiency and the energy efficiency was evaluated using LHV and HHV as a calculation base. To determine the exergetic efficiency two methodologies were used: input/output and exergy balance. This last one has been 
proposed to calculate bagasse boilers, but it can be applied to others wet fuels boilers. The first law analysis, which uses HHV as calculation base showed to be more adequate than LHV one; since the important effect of bagasse moisture content on boiler performance can be observed. In addition, it can be seen that the exergy balance method gave more information about the bagasse boiler performance. The exergy balance allows pointing out the irreversibilities that happen in the boiler, which could help to improve its efficiency.

The second law applied to bagasse boiler allows perceiving the boiler performance improvements when the steam pressure and temperature are increased. This fact is not perceived through the first law application. Finally, the case IV of boiler equipment scheme has shown better performance than the others.

\section{Acknowledgements:}

The authors wish to thank to $\mathrm{CNPq}$ (PQ 10 307068/2006-4), FINEP (Contract FINEP - FUNCAMP Nr. 01/06/004700) and Equipalcool Sistemas Ltda for their support during the development of this work.

\section{References:}

Acosta, J. (1995) The boiler efficiency fueled bagasse. Int. Sugar Journal; 97,(1158), 248-255.

ASME PCT 4.1(1975) Steam Generating Units. Power test codes, The American Society of Mechanical Engineers, United Engineering Center, New York N.Y. 10017.

ASME PCT 4(1998) Fired Steam Generators. The American Society of Mechanical Engineers, Three Park Avenue. New York N.Y. 10016 - 5990.

Beatón, P., Lora E. (1991) Thermal balance test in bagasse boilers. Departamento de Termoenergética, Facultad de Ingenieria Mecánica. I.S.P.J.A.M., Cuba, (in Spanish).

Cárdenas, G., Paz, D., Wittwer, E. (1994) Energy and Exergy analysis of a combined bagasse dryer-boiler system, Int. Sugar Journal, 96(1146), 213-219.

Cortez L.A.B., Gómez, E.O. (1998) A method for exergy analysis of sugarcane bagasse boilers, Braz. J. of Chem. Eng. 15 (1), 1-8.

Kamate S.C., Gangavati, P.B. (2010) Energy and Exergy Analysis Of a 44-MW Bagasse-based Cogeneration Plant in India, Cogeneration and Distributed Generation Journal, 25, 35-51.

Kotas, T. J. (1995). The Exergy Method of Thermal Plant Analysis, Krieger Publishing Company, Florida.
Lozano, M. A. (1987), Methodology to exergetic analysis of Thermal Center steam boilers, (Doctoral Thesis), University of Zaragoza, Zaragoza, Spain.

Prieto, M.G., Nebra, S.A. (2004), Thermodynamic and Exergetic Cost Analysis of Two Steam Based Cogeneration Schemes proposed for a Brazilian Sugar Mill ECOS2004, Proceedings of- $17^{\text {th }}$ International Conference on Efficiency, Cost, Optimization, Simulation and Environmental Impact of Energy Systems, Guanajuato, México, July 7 - 9 , 3, 1023 1030.

Sosa-Arnao, J. H.; Nebra, S. A.,(2005), The Exergy of Sugar Cane Bagasse; Proceedings of 14th European Biomass Conference \& Exhibition: Biomass for Energy, Industry and Climate Protection, 17-21 October, Palais des Congrès, Paris, France.

Sosa-Arnao J.H., Modesto M., Nebra, S.A(2006 $)$. Two proposals to determine the efficiency of bagasse boiler. Proceedings of 6th International Congress on Distributed Generation and Energy in Rural Environments, Campinas, in CD-ROM.

Sosa-Arnao J.H., Nebra, S.A. (2006b), Second law applied on boiler fueled by sugar cane bagasse. Proceedings of the $11^{\text {th }}$ Brazilian Congress of Thermal Sciences and Engineering - ENCIT 2006, Braz. Soc. of Mechanical Sciences and Engineering - ABCM, Curitiba, Brazil,Dec. 5-8, Anais em CD-Rom.

Sosa-Arnao, J. H. Nebra, S., Corrêa, J. L., Silva, M. (2006c) Sugar Cane Bagasse Drying - A Review, Int.Sugar Journal, CVIII, .372-380.

Sosa-Arnao J.H., Nebra, S.A. (2007), First and second law analysis applied on boilers fuelled by sugar cane bagasse. ECOS 2007 Proceedings of 20th International Conference on Efficiency, Cost, Optimization, Simulation and Environmental Impact of Energy Systems, Padova, Italy, June 25-28, I,847-854.

Sosa-Arnao, J.H.; Nebra, S.A.(2009), Bagasse Dryer Role in the Energy Recovery of Water Tube Boilers, Drying Technology, 27 (4), 587-594.

Szargut, J., Morris, D., Steward, F(1988). Exergy analysis of thermal, chemical, and metallurgical process. Hemisphere Publishing Corporation.

van der Poel, P. W., Schiweck, H., Schwartz, T. (1998) Sugar Technology Beet and Cane Sugar Manufacture, Berlin, Verlag Dr. Albert Bartens KG, Germany.

Wittwer, E. (1993), Die Exergie der Bagasse. Zuckerindustrie, 118 (11), 859-862 (in German). 